\title{
Experiências do estigma na depressão: um estudo transcultural ${ }^{1}$
}

\author{
Virginia Moreira ${ }^{2}$ - Universidade de Fortaleza, Brasil
}

Thabata Castelo Branco Telles - Universidade de Fortaleza, Brasil

\begin{abstract}
Resumo
$\mathrm{Na}$ pesquisa $O$ significado da depressão na contemporaneidade: um estudo crítico-cultural no Brasil, Chile e Estados Unidos (Moreira, 2007), uma das categorias emergentes da análise fenomenológica das entrevistas foi o estigma. Este artigo retoma esse resultado, buscando aprofundar a compreensão da experiência vivida do estigma em pessoas diagnosticadas com depressão nos 3 países. Com este fim, foram reanalisadas fenomenologicamente 51 entrevistas ( $n=15$, em Fortaleza; $n=20$, em Santiago; e $n=16$, em Boston). Os resultados apontam peculiaridades em cada país, mostrando o conteúdo qualitativamente diferente da experiência vivida do estigma na depressão nos três países. Só no Brasil aparecem conteúdos relacionados à preocupação com a evitação do estigma; apenas no Chile, o estigma foi encontrado associado à culpa, vergonha e falta de privacidade; e unicamente nos Estados Unidos o estigma aparece relacionado ao racismo, o que possivelmente estaria relacionado a diferenças culturais.

Palavras-chave: Depressão; Estigma; Transcultural; Fenomenologia.
\end{abstract}

\section{Experiences of stigma in depression: a cross cultural study}

\begin{abstract}
From the research The meaning of depression in contemporary world: a critic-cultural study in Brazil, Chile and the United States (Moreira, 2007), one of the emerged categories in the phenomenological analyses of the interviews was the stigma. This article retakes this study, aiming to comprehend the lived experience of stigma in people diagnosed with depression in the three countries. It had been phenomenologically re-analyzed 51 interviews ( $n=15$, in Fortaleza; $n=20$, in Santiago; $n=16$, in Boston). The results point peculiarities in each country, showing the qualitatively different content of the lived experience of stigma in depression in the three countries: only in Brazil it is mentioned the concern with how to avoid stigma; only in Chile, stigma is associated to guilt, shame and lack of privacy; and only in the United States, stigma is related to racism, which could be associated to cultural differences.
\end{abstract}

Keywords: Depression; Stigma: Cross-cultural; Phenomenology.

\section{Introdução}

A crescente quantidade de diagnósticos de depressão é notória no mundo inteiro. Tem-se hoje a depressão como uma das formas mais comuns de doença mental (Hinshaw \& Cicchetti, 2000; Moreira, 2007; Patel \& Kleinman, 2003; Scliar, 2003).

A depressão atualmente aumenta os custos em saúde pública, além de contribuir para a incapacidade produtiva (Patel \& Kleinman, 2003;

\footnotetext{
1 As autoras agradecem à FULBRIGHT, CAPES e UNIFOR pelo financiamento da pesquisa como projeto de Pós-Doutorado no Departamento de Medicina Social de Harvard Medical School (2002-2003), que originou este artigo. Agradecem ainda à Byron Good (DSM-HARVARD), Irene Magaña (USACH-Chile), Karynne Melo (UNIFOR), Mary Gregorio (Center House, Boston) e à equipe do Laboratório de Psicopatologia e Psicoterapia Humanista Fenomenológico Crítica (APHETO) por suas preciosas contribuições.

2 Endereço para correspondência:

Laboratório de Psicopatologia e Psicoterapia Humanista Fenomenológico Crítica (APHETO) - Mestrado em Psicologia Universidade de Fortaleza. Av. Washington Soares, 1321- Edson Queiroz - 60811-341 - Fortaleza, CE - Brasil. E-mail: virginiamoreira@unifor.br
}

Scliar, 2003). Essas são algumas razões para o grande interesse em pesquisas acerca de tratamentos relativos à doença mental, onde as intervenções psicológicas e psicofarmacológicas aparecem como mais eficazes (Patel \& Kleinman, 2003). Nos últimos 60 anos, é marcante o desenvolvimento da indústria farmacêutica, existindo atualmente no mercado antidepressivos e ansiolíticos de última geração que vêm sendo consumidos em alta escala (Gordon, 2002). Hoje, não é apenas o psiquiatra quem prescreve antidepressivos ou ansiolíticos, mas os médicos e profissionais de saúde em geral (Moreira, 2001 e 2007; Moreira \& Sloan, 2002). Não é por acaso qu,e desde os tempos da alquimia, já se reconhece o mercado farmacêutico como um dos mais rentáveis (Scliar, 2003). Concomitantemente a estes avanços psicofarmacológicos, tem-se a crescente quantidade de diagnósticos de depressão, o que também possivelmente se deve ao grande desenvolvimento tanto no campo do diagnóstico das desordens mentais, quanto no campo da epidemiologia (Corrigan \& Lundin, 2001; Moreira, 2007; Moreira \& Callou, 2006).

Ainda que a ênfase maior para o 
tratamento da depressão se encontre na linha psicológica e, principalmente, psicofarmacológica, dentro da visão biomédica predominante na contemporaneidade, pesquisas apontam o estigma como grande fonte de sofrimento na depressão (Corrigan \& Lundin, 2001; Hinshaw \& Cicchetti, 2000; Kleinman, 1988; Moreira, 2007; Kurihara \& cols.., 2000; Patel \& Kleinman, 2003). Atitudes de estigma perante o doente mental se encontram influenciadas por fatores como raça, cultura e crenças religiosas. Cerca de dois terços de pessoas que sofrem de transtornos mentais não procura ajuda em razão de fatores como o estigma, o que se constitui num problema tanto para os doentes mentais, como para seus familiares (Hinshaw \& Cicchetti, 2000). Esse dado, entre outros, indica a necessidade de pesquisas sobre o estigma com base nas experiências vividas das pessoas com doenças mentais (Kleinman, 1995; Link \& Phelan, 2001), identificando os processos sociais e culturais presentes no cotidiano dos indivíduos e de suas famílias, como são tratados os dilemas morais e as possibilidades da vida para aqueles afetados (Good, 2002).

Neste estudo, entendemos estigma como uma situação onde o sujeito não se encontra habilitado para uma aceitação plena da sociedade; é uma marca diferencial de valor pejorativo, que inferioriza, sendo estabelecida a partir de critérios impostos arbitrariamente nas relações sociais cotidianas (Goffman, 1988). Na perspectiva fenomenológica baseada na filosofia de MerleauPonty, o estigma é compreendido de forma "mundana", isto é, na interseção do singular com o universal, do individual com o social, na relação de mútua constituição entre o homem e o mundo (Moreira \& Guedes, 2007).

O estigma foi um dos temas emergentes em pesquisa transcultural anterior sobre a experiência vivida da depressão (Moreira, 2007), que tinha como pergunta norteadora: "Que relação você encontra entre o seu jeito de viver e sua depressão?" Naquela pesquisa, desenvolvida no período 2002-2004, realizamos entrevistas fenomenológicas com 72 sujeitos colaboradores adultos, em serviços de saúde públicos em Fortaleza, no Brasil; Santiago, no Chile; e Boston, nos Estados Unidos. Um dos resultados emergentes foi o tema estigma, associado pelos entrevistados a sua experiência de depressão.

Este artigo descreve um estudo que dá continuidade àquele, retomando, especificamente, o tema do estigma com o objetivo de aprofundar qualitativamente sua compreensão. Com este fim, reanalisamos fenomenologicamente as entrevistas, sem nos determos nos vários outros temas emergentes naquela pesquisa - tais como descrição dos sintomas, solidão, trabalho, luto e processos de perda, remédios, história familiar de violência, abuso e alcoolismo, trabalho, acúmulo de tarefas e competição, desemprego e dificuldades econômicas, religiosidade - como associados ao fato de ter depressão, além do estigma (Moreira, 2007).

Entendendo que "as condições humanas se restringem à experiência vivida” (Kleinman, 1995, p. 98), consideramos a importância de trabalhar a partir de relatos de pessoas que vivenciaram ou vivenciam a situação que queríamos pesquisar: a experiência de estigma. Considerando a singularidade das situações de experiência vivida, tivemos como objetivo aprofundar a compreensão do fenômeno: o estigma vivido na depressão.

\section{Método}

Foi utilizado o método fenomenológico crítico para re-analisar as entrevistas, tal como havia sido feito na pesquisa anterior. Este método se utiliza de instrumentos que priorizem a experiência (aqui utilizamos as entrevistas), tendo em vista que, em vez de buscar uma essência, o pesquisador estará buscando o significado da experiência vivida. Tratando-se de um método intimista, dá margem ao aprofundamento qualitativo do que está sendo pesquisado. A análise fenomenológica crítica, ou mundana, com base no pensamento de Merleau-Ponty, inclui como última etapa de análise o "sair do parêntese", onde o pesquisador deixa de praticar a redução fenomenológica para assumir sua posição mundana, evitando o pensamento de sobrevôo (Moreira, 2004).

Foram reanalisadas fenomenologicamente 51 entrevistas ( $\mathrm{n}=15$ em Fortaleza; $\mathrm{n}=20 \mathrm{em}$ Santiago; e $\mathrm{n}=16 \mathrm{em}$ Boston), da pesquisa sobre o significado da experiência vivida da depressão no Brasil, Chile e Estados Unidos (Moreira, 2007). Nosso critério de inclusão para sujeitos colaboradores foi eles serem adultos, de ambos os sexos, nascidos e residentes em cada país especificamente, tendo o diagnóstico de depressão, e serem pacientes do serviço de saúde pública em cada uma dessas cidades. Em Fortaleza entrevistamos pacientes do Serviço de Psicologia Aplicada do NAMI, na Universidade de Fortaleza, e do CAPS - Centro de Atenção Psicológica de Fortaleza; em Santiago entrevistamos pacientes do 
CAP - Centro de Atención Psicológica de la Escuela de Psicología de la Universidad de Santiago de Chile e em Boston tivemos como sujeitos colaboradores freqüentadores da Center House.

Foram realizadas entrevistas fenomenológicas semi-estruturadas com duração de tempo indeterminado. A entrevista fenomenológica é um instrumento que visa apreender a experiência vivida do sujeito, possibilitando, no caso desta pesquisa, uma compreensão detalhada da experiência vivida da depressão na perspectiva do indivíduo doente (Moreira, 2004). Nossa pergunta disparadora era: "Como você relaciona seu jeito de viver a ter depressão?”. Após essa pergunta os entrevistadores conduziam a entrevista sempre retornando à pergunta inicial buscando que o entrevistado descrevesse sua experiência. Bolsistas de pesquisa devidamente treinados no método fenomenológico realizaram as entrevistas em Fortaleza e em Santiago. Em Boston, a primeira autora desta pesquisa realizou as entrevistas.

O método de reanálise consistiu em uma adaptação do método fenomenológico mundano (Moreira, 2004) mediante os seguintes passos: 1. Releitura das transcrições literais das entrevistas em seu respectivo idioma (português, espanhol e inglês); 2. Divisão do texto nativo da entrevista em movimentos, de acordo com o seu "tom"; 3 . Análise descritiva do sentido que emerge de cada uma das seções; 4. "Saindo dos parênteses" - é nesse momento que o pesquisador retorna às suas hipóteses iniciais para melhor compreender seu objeto de estudo, ou seja, nesse momento deste estudo enfocamos especificamente o estigma na experiência vivida da depressão dos sujeitos colaboradores. Este método de reanálise foi semelhante ao da pesquisa anterior realizada entre 2002 e 2004, com a diferença que neste momento "deixamos de lado" outros temas emergentes e focalizamos apenas os temas relacionados com o estigma na experiência vivida da depressão.

\section{Resultados e discussão}

A questão de o que é normal para uma cultura poder não ser para outra, vem sendo amplamente discutida, (Kleinman, 1995; Moreira, 1998, 2000, 2001; Scliar, 2003; Tatossian, 2001), daí a importância de um estudo transcultural como este, que pode contribuir para a compreensão qualitativa do ponto de vista cultural, como parte do lebenswelt (mundo vivido). Tendo isso em mente, as 51 entrevistas foram reanalisadas por país. Vale assinalar que, em Fortaleza, 13 das 15 entrevistas apresentaram conteúdos que relacionavam depressão e estigma. Em Boston, 13 dentre 16 entrevistas reanalisadas, tinham o estigma como tema emergente e em Santiago, 18 dentre 20 entrevistas aludiam ao estigma como parte da experiência vivida na depressão. Uma análise mais detalhada das falas dos sujeitos colaboradores que aludiram ao estigma como parte da experiência vivida na depressão mostra o seguinte:

\section{No Brasil}

- Estigma perante exigências

Alguns entrevistados relataram se sentirem diminuídos ou pressionados quando submetidos a exigências, associando esta experiência ao fato de terem depressão:

"Eles queriam tudo pra ontem, sabe? [...] Ai eu chorava todo dia... todo dia eu chorava acolá".

"Eu sou obrigada a me levantar na marra pra fazer alguma coisa pra ninguém me cobrar de mim".

"Só que eles exigem coisas que você não sabe, porque você não tem experiência na área, no ramo e querem tudo pra amanhã [...] Então eu sou uma pessoa muito sensivel. Eu sou muito sensivel, sou muito preocupada também. Então se eu não der de conta en fico muito ansiosa, en fico angustiada. E isso acontece tanto no emprego, quanto no meio familiar".

Ser exigido no trabalho ou na família passa a ser um fator que contribui para a depressão, quando esta pessoa tem a doença. Ou seja, tendo em vista os sintomas clássicos de depressão, tais como falta de energia, dificuldade de levantar pela manhã, choro fácil e freqüente, sensibilidade exagerada, entre outros, quando a pessoa que vive estes sintomas se vê exigida a produzir, passa a se deprimir ainda mais. Este resultado corrobora pesquisas anteriores que apontam que a depressão é vivida como uma experiência de "despotencialização" na contemporaneidade (Moreira, 2007; Moreira \& Sloan, 2002).

- Estigma relacionado à incompreensão ou compreensão negativa da depressão

A palavra depressão é usada para se referir a um declínio, tanto para questões relativas à agricultura como economia, por exemplo. Essa associação é comumente realizada ao citarmos este 
nome como doença (Scliar, 2003). Isto propicia uma compreensão negativa, ou pejorativa da doença, levando a pessoa que tem depressão a se sentir temerosa de ser taxada como louca, ou, em outros casos, desacreditada, incompreendida; em ambos os sentidos, a pessoa se sente desvalorizada, inferiorizada, estigmatizada:

"Eu vou procurar agradar a pessoa da medida que eu puder agradar, tratar da melhor maneira possivel porque boje en sou desacreditada, porque acham que en sou doida, porque tenho depressão. Então se en fizer, se eu disser um tantinho assim de algo, ai vão dizer: ela é doida, por isso fez isso assim, assim comigo, ela é doida! Então é muito difícil assim nosso quadro, né doutora? Por parte dessa parte aí, porque a gente... eu, no meu caso, eu tento agradar, eu tento concordar com o que as pessoas direm para não entrar em conflito com as pessoas, pra não dar uma confusão, pra não dar uma desavença e pra mim não ficar taxada de uma louca, que eu sou doida, que eu só faço aquilo porque eu sou doida, eu... ta entendendo?"

Essa fala ilustra a submissão vivida pela pessoa que tem depressão, sentindo-se inferiorizada pelo estigma da loucura, tal como tradicionalmente estudado por Goffman (1988). Mas outras falas ilustram uma outra forma de experiência estigmatizada na depressão, pelo seu caráter "invisível”, tal como encontrado também em pesquisas anteriores, onde ter depressão é incompreendido pela sociedade, como se fosse uma decisão da própria pessoa, ou mesmo como se estar deprimido fosse ser preguiçoso (Moreira, 2006), fazendo com que a pessoa vivencie o estigma:

"Só quem sabe o que é uma depressão é quem ta com ela, porque a gente sente uma confusão na cabeça, a pessoa não dorme, a pessoa se sente inútil, né? Ai às vezes a familia não dá apoio, a minha família não dá apoio. Só tinha um filho que me dava apoio. O resto dizia que era não era nada, que era preguiça...”.

"Muitas pessoas acham que depressão é uma doença besta, que você pode chegar e dižer assim: ah, levanta a cabeça, vai passear, você vai conseguir tudo, vai conversar com outras pessoas... mas, negativo, isso não tem validade no processo depressivo".

Estudos constatam que pessoas que são bem informadas sobre doença mental tendem a ser menos preconceituosas e mais compreensivas com o doente mental, reduzindo o estigma (Corrigan \& Lundin, 2001; Hinshaw \& Cicchetti, 2000;
Kurihara \& cols., 2000). Um maior nível de informação sobre a patologia da depressão provavelmente contribuiria para a diminuição da incompreensão aludida pelos entrevistados, que passam a sofrer não apenas pela doença, mas pelo fato de não se sentirem compreendidos.

- Estigma relacionado à sensação de incapacidade

Apesar de estar associado ao estigma relacionado à exigência, esta temática foi colocada à parte por apresentar falas ilustrativas que retratam explicitamente a sensação de incapacidade, vivenciada como uma experiência que inferioriza, que desvaloriza; sentir-se incapaz parece quase sinônimo de sentir-se inferiorizado, estigmatizado:

"É como se fosse assim a vida da gente é colorida, é cheia de prazeres, é cheia de tudo de bom, mas no momento que você está passando por esse processo depressivo, acaba todo esse colorido da vida, você deixa de fazer os seus planos de vida, você não tem planos para o futuro, você vive eternamente angustiado e é aconselhável pelos médicos que quando você está passando por esse processo depressivo, você não deve tomar decisões nenhuma na sua vida [...] você não pode, de maneira nenhuma, tomar decisão porque você não tem capacidade".

"Uma mãe que não pode tomar conta de casa, que não pode educar os filhos direitinho como é para ser [...] então eu acho que eu não sou nem capaz de educar minhas filhas por causa do problema".

"É minha família vive em função de mim. Eu sou o barco que navega com o pessoal. E agora o barco está afundando".

\section{- Duplo estigma}

Em alguns casos, foi colocado não apenas o estigma relacionado à depressão, como também o estigma relacionado a outros fatores tais como sexualidade, classe econômica, idade. Ou seja, foi encontrado nas falas um duplo estigma:

"É uma coisa que... sobre... sobre isso aí, já... geralmente a maioria das pessoas, não vou dizer todas, mas a maioria das pessoas que tem problemas de depressão geralmente são causadas por distúrbios sexuais"

"O grande problema que acontece com a relação entre essa minha depressão e o meu modo de vida, podia me atingir era as questões sociais. Eu não tenho problema. Se eu não tivesse uma familia pra dar satisfação, eu já tava com uma 
associação de gay aí, em defesa dos gays, tava lutando aí, defendendo esse povo, que eu sou uma pessoa assim. Então isso pra mim... a única coisa que perturba é só que eu não quero... eu não quero envergonhar meus filhos, eu não quero envergonhar minha mulher, eu não quero... eu quero ficar sempre... por isso que eu tenho vontade de morrer porque eu morrendo acaba, acabou-se".

"A convivência com o marido, ao desprezo do marido, a essa discriminação... eu agora digo assim, que sou discriminada por três coisas: discriminada pelo marido, discriminada porque sou velha e discriminada porque moro num bairro pobre, no Pirambü".

- Modos de tentar evitar o estigma

As seguintes falas ilustram formas de a pessoa evitar sentir-se estigmatizada:

"Já é chamando atenção pra dizer pra eles que eu sou uma pessoa capaz."

"Tem hora que eu tenho vontade de pegar assim... quando eu tô com meus nervo atacado... os meu menino não chega nem perto, eles já sabe. Eu digo logo: Hoje eu não quero conversa com ninguém. Eles diz: Vixe, a mãe já ta com raiva. Eu digo: menino, me deixa, é os meu remédio... É que eu sou assim, quando eu tô no meu momento de raiva eu sou capaz de quebrar a casa todinha, eles já sabe é tanto que nem mexe comigo..."

É interessante observar que só no Brasil aparecem nas falas dos entrevistados as tentativas de estratégias de evitação do estigma, aludidas por Corrigan e Lundin (2001). Esse fato pode levar a pensar em uma possível faceta cultural do modo de existir do brasileiro através do "jeitinho brasileiro" (Barbosa, 1992). Estariam estes entrevistados tentando dar um jeitinho para evitar o estigma?

\section{Chile}

- Estigma relacionado à exigência

Os chilenos relataram, na maioria das vezes, uma dupla exigência: a de ser bom pai/mãe e trabalhador. Esta dupla exigência apareceu de modo mais forte ainda que no Brasil:

"Y ahi vienen las discusiones y que pucha porque no trabajo, pero yo hago hartas cosas, en realidad, entonces eso me hace sentir que soy mala, que soy... Eso es lo que mas me deprime, me da rabia, porque, no tengo el apoyo de lellos asi como trabajo tengo que hacer las cosas también en la casa"”.

"Si, todos los dias nos evaluan o todas las semanas, entonces ahora mis notas son, altas, y cuando yo estaba con depresión mis notas eran bajas, porque trataba horrible a los clientes, no me importaba... si ellos me gritaban yo gritaba más fuerte"4.

- Estigma associado à depressão e culpa

Esta fala de um sujeito colaborador chileno ilustra a associação feita entre sensação de culpa, depressão e o fato de sentir-se diminuído, estigmatizado:

"Pesada, cuando le digo algo, que me dice, justed tiene la culpa!"'5.

- Estigma relacionado à vergonha da doença

A vergonha, experiência diretamente ligada ao estigma aparece explicitamente na fala de alguns chilenos:

"Yo me quedo acomodata y no pienso salir a la calle, y claro porque me daría vergüenza" $a$.

"Dame vergüenza porque es mi enfermedad, creo yo, ¿la depresión es una enfermedad no?"”.

"Después me da vergüenza estar mal"s.

É interessante observar que a vergonha não é mencionada pelos sujeitos colaboradores brasileiros. Estudos anteriores sobre a subjetividade do brasileiro e do chileno mostram que a cultura chilena é tida como mais contida e formal, em relação à brasileira, tida como mais solta e informal (Moreira, 1999). Nesse sentido, a cultura chilena estaria influenciando na experiência vivida da vergonha associada ao fato de ter depressão.

\footnotetext{
3 "e aí vêm as discussões e que, puxa, porque não trabalho, mas eu faço fartas coisas, na realidade, então isso me faz sentir que sou má, que sou... Isso é o que mais me deprime, me dá raiva, porque, não tenho o apoio deles assim como trabalbo tenho que fazer as coisas também em casa".

4 "sim, todos os dias nos avaliam ou todas as semanas, então agora minha notas são altas, e quando eu estava com depressão, minhas notas eram baixas, porque tratava horrivelmente os clientes, não me importava... se eles gritavam comigo en gritava mais forte".

5 "pesada, quando digo algo a ele, que me diæ: "você tem a culpa!".

6 "eu fico acomodada e não penso em sair à rua, e claro porque me daria vergonha".

7 "me dá vergonha porque é minha doença, creio eu, a depressão é uma doença, não?".

8 "depois, me dá vergonha estar mal".
} 
- Estigma relacionado à incompreensão perante a doença

De maneira similar ao que foi observado no Brasil, no Chile também foi associado o estigma à falta de compreensão da doença:

"En el sentido de que él, no sé si no sabia como entenderme, como manejarme, que él no me dejaba que yo biciera lo que yo quisiera, pero él no trataba de él incentivarme"'.

"Yo siempre decía quisiera que alguien me escuchara lo que yo, lo que como soy yo, lo que siento, lo que vivo y nadie me escucha"10.

- Duplo estigma

O duplo estigma também aparece nas falas dos chilenos: aqui o estigma da depressão está entrelaçado ao da pobreza, como no Brasil, mas aparece um conteúdo novo, que é o da sociabilidade:

"Yo para mi mujer siempre fui menos, para ella y su familia yo era el pobre inútil, incapaz. de satisfacer los gustos de mi señora"11.

"Además para mi esposa yo era muy poco sociable, no compartía mucho con sus compañeros de trabajo y la verdad es que para mi era bien complicado participar de sus reuniones por que yo no encajaba mucho en los temas de conversación ni de las cosas que a ellos les gustaban"12.

- Estigma relacionado à necessidade de dar satisfação à sociedade

Esta temática surgiu no Brasil, porém de modo muito sutil. No Chile, ela apareceu de maneira bem mais clara, o que também dá margem a reflexões a respeito da cultura chilena como mais rígida socialmente que a brasileira, tal como indicam pesquisas anteriores (Moreira, 1999):

"Entonces todo el mundo se conoce, el pelambre es grande, abi es terrible y sino, ósea si no te ven haciendo na' te

\footnotetext{
9 "no sentido de que ele, não sei se não sabia como me entender, como me manejar, que ele não me deixava fazer o que eu queria, mas ele não tratava de me incentivar".

10 "en sempre dizia queria que alguém me escutasse o que eu, o que como sou, o que sinto, o que vivo e ninguém me escuta".

11 "eu para minha mulher sempre fui menos, para ela e sua familia eu era o pobre inutil, incapaz de satisfazer os gostos da minha mulber".

12 "além disso, para minha esposa eu era muito pouco sociável, não compartilhava muito com seus companheiros de trabalho e a verdade é que pra mim era bem complicado participar das suas reuniões porque eu não me encaixava muito nos temas de conversa nem das coisas que eles gostavam".
}

inventan pero algo bay"'13.

"Y eso me ha becho sentir que tengo que estarlo baciendo, tengo que estar haciendo reír a los demás, como si siempre estuviera bien"14.

- Estigma relacionado à falta de privacidade

O fato de a pessoa com depressão se sentir sem privacidade por conta da sua depressão se relaciona ao fato dela se sentir fragilizada, o que daria aos outros o direito de invadi-la, ou proibi-la de ter amigos. Mais uma vez, vale observar que este significado não apareceu nas entrevistas brasileiras, o que leva a pensar em que medida no Brasil, ou pelo menos em Fortaleza, na classe social mais baixa, onde foram recrutados os sujeitos colaboradores (que se utilizavam de serviços de saúde públicos gratuitos), a vida privada não tem lugar ou importância, onde a casa, é a rua (DaMatta, 2003) diferentemente do Chile:

"No sé, y eso como que me hace sentir mal también, porque ellos deben pensar que yo soy débil no sé que soy tonta, porque siempre se están metiendo en las cosas mías en mi casa"15.

"No, no tengo espacio para mí, no, no tengo privacidad para mi"16.

\section{Estados Unidos}

- Estigma associado à exigência

Nos Estados Unidos a exigência, que apareceu também no Brasil e no Chile, se refere especificamente a questões financeiras e de trabalho. Foi relatada a exigência de se trabalhar e ter dinheiro como associada à depressão e estigma:

"I internalized some of society values on depression which is: lack of productivity, lack of being a member of the consumer society because I have no money to spend in anything" "17.

"Ah, I feel depressed when I 'm not working, when I don't

\footnotetext{
13 "então, todo mundo se conbece, a falação é grande, ai é terrivel e mas, on seja, não te vêem fazendo nada mas te inventam, mas algo há".

14 "e isso me fez sentir que tenho que estar fazendo os outros rirem, como se sempre estivesse bem".

15 "não sei, e isso como que me far sentir mal também, porque eles devem pensar que sou débil, não sei que sou tonta, porque sempre estão se metendo nas minhas coisas na minha casa".

16 “não, não tenho espaço para mim, não, não tenho privacidade pra mim”.

17 "eu internalizei alguns valores da sociedade na depressão que são: falta de produtividade, não ser um membro de consumo da sociedade porque eu não tenho dinheiro para gastar em nada".
} 
have the money"18.

As falas acima, com relação a se sentir exigido, se diferenciam claramente das chilenas e brasileiras no que diz respeito ao tipo de exigência. Nos norte-americanos, a experiência vivida do estigma associada a ser exigido diz respeito explicitamente a ser produtivo financeiramente. Aqui cabe, mais uma vez, uma reflexão do ponto de vista cultural, que lembra que a sociedade norte-americana é tida como a sociedade do "time is money". Não que o Brasil ou o Chile não sejam sociedades capitalistas. Mas chama a atenção que o aspecto de não ser produtivo em termos financeiros apareça na experiência de se sentir diminuído e estigmatizado pelo fato de não poder trabalhar e ganhar dinheiro por conta da doença, merecendo também futuras pesquisas qualitativas que investiguem mais a fundo este fator estigmatizante associado à depressão.

- Estigma por não estar de acordo com cultura capitalista

Aqui, as falas dos entrevistados de Boston são ainda mais explícitas em relação ao fato de se sentirem estigmatizados por não corresponderem a um modo de existir da cultura capitalista individualista que segundo Sennett (2006), se sobrepõe às estruturas familiares:

"I don't reply because they represent an attitude or value systems that I'm not agree with but I don't fight with nobody [...] but I tried do.... make the best relationship possible based on what I think is right"19.

- Estigma relacionado ao sentimento de nãoaceitação

Pode-se perceber relatos de pouco contato social entre os norte-americanos, o que está bastante relacionado ao sentimento de nãoaceitação por parte da sociedade que faz com que o sujeito colaborador se sinta não querido, não valorizado, diminuído, excluído, solitário (Moreira \& Callou, 2006), vivenciando, assim o estigma por ter depressão:

"Well, I thought no one wanted to spend time with me"20.

\footnotetext{
18 "ah, eu me sinto depressivo quando não estou trabalhando, quando eu não tenho o dinbeiro".

19 "eu não replico porque eles representam uma atitude ou sistemas de valor que eu não concordo, mas eu não brigo com ninguém (...) mas eu tento estabelecer a melhor relação possivel baseada no que eu penso que seja certo".

20 "bem, eu achava que ninguém queria ficar comigo".
}

"When I go home the depression just left"21.

'Don't have many friends. It's hard to make friends in Boston, I don't know (...) nobody talks to each other in the subway" 22 .

Aqui cabe, mais uma vez, uma discussão do ponto de vista cultural: em Boston, ao contrário de Fortaleza e Santiago, a maioria dos entrevistados vivia só, longe de suas famílias, sustentados pelo "social security" (seguro social), o que não é possível em paises como o Brasil ou o Chile. No Brasil, muitas vezes a aposentadoria por invalidez por conta de uma doença mental é usufruída por toda uma família, que vive com o doente, muitas vezes até as suas custas. Vale observar que, ainda que contando com o amparo financeiro, os sujeitos colaboradores associam sua depressão à solidão (Moreira \& Callou, 2006), vivendo o desamparo que, segundo Scliar (2003) caracteriza a cultura individualista, tal como a norte-americana.

\section{- Duplo stigma}

Nas falas de Boston o estigma em relação à depressão se encontra entrelaçado ao estigma em relação à sexualidade (que apareceu também no Brasil) e ao racismo (que não aparece nem no Chile nem no Brasil):

'He said: 'I don't think you like girls'; I said: 'I like girls'. He told to somebody that I was gay! Just because I never had sexual intercourse! That's not nice to say by a person!'23.

\section{"Racism (makes me depressed)" 24 .}

Nos Estados Unidos, assim como no Chile e no Brasil, vemos um duplo estigma, mas aqui ele é qualitativamente diferente, pois só nos entrevistados norte-americanos encontramos mencionada a questão do racismo, o que estaria associado à cultura de seu país, onde o racismo faz parte da história de forma marcante.

\footnotetext{
21 "quando eu vou pra casa a depressão simplesmente vai embora".

22 "eu não tenho muitos amigos. É difícil se fazer amigos em Boston, eu não sei (...) ninguém fala com o outro no metrô".

23 "ele disse: 'eu não ac "e aí vêm as discussões e que, puxa, porque não trabalho, mas en faço fartas coisas, na realidade, então isso me faz sentir que sou má, que sou... Isso é o que mais me deprime, me dá raiva, porque, não tenho o apoio deles assim como trabalho tenho que fazer as coisas também em casa". ho que você gosta de garotas'; eu disse:'eu gosto de garotas'. Ele disse pra alguém que eu era gay! Só porque en nunca tive uma relação sexual! Não é legal dizer isso de uma pessoa".

24 "racismo (me deprime)".
} 
$\mathrm{Na}$ pesquisa anterior (Moreira, 2007), foram encontrados resultados semelhantes, tais como a questão do racismo nos Estados Unidos, da incompreensão com relação à doença no Chile, e do duplo estigma no Brasil. Esses resultados relativos ao estigma encontram-se aqui mais detalhados e aprofundados do ponto de vista qualitativo.

\section{Considerações finais}

Este estudo mostra que a experiência vivida do estigma na depressão existe no Brasil, no Chile e nos Estados Unidos, tal como encontramos na pesquisa anterior (Moreira, 2007), associado à sensação de não-aceitação, do medo de ser visto como louco, da sensação de incapacidade ao ser exigido, à sexualidade. A contribuição desta nova pesquisa aqui descrita foi de mostrar que o estigma é, em alguns pontos, qualitativamente diferente em cada país, o que poderia ser relacionado a aspectos culturais, já que alguns temas foram mencionados em apenas um país:

Apenas no Brasil tem-se o estigma por se sentir incapaz relacionado aos modos de evitar o estigma. Dado que estratégias de evitação do estigma não são mencionadas no Chile e nos Estados Unidos, pode-se pensar que sua menção no Brasil possivelmente se encontra relacionada ao modo de constituição da subjetividade do brasileiro, onde há o "jeitinho", em que se tenta solução para tudo. Esse sujeito se percebe com dificuldades para encontrar soluções e se sente incapaz. Porém, o "jeitinho brasileiro" se manifestaria na tentativa de evitar o estigma.

Apenas no Chile o estigma foi encontrado associado à culpa, vergonha e falta de privacidade. É um país onde a subjetividade de seus habitantes estaria associada a sua geografia mais isolada, onde o chileno se vê "nos confins do mundo", tratandose de uma sociedade aparentemente mais rígida, ou, pelo menos, menos não tão solta como a brasileira.

Nos Estados Unidos se observa uma forte presença dos valores de uma cultura capitalista e individualista na experiência vivida do estigma na depressão, o que possivelmente faz com que os entrevistados norte-americanos se sintam estigmatizados principalmente por serem incapazes de produzir. A pressão pela necessidade de trabalhar apareceu também nas falas dos chilenos e brasileiros, mas ela é notoriamente mais explícita nas falas do pacientes norte-americanos. Já a experiência vivida do estigma associado duplamente à depressão e ao racismo apareceu apenas nos Estados Unidos. Sabe-se que tanto no Brasil como no Chile existe racismo. No entanto, este faz parte da história dos Estados Unidos de maneira muito mais marcante, o que indica, mais uma vez, a presença da cultura na experiência vivida quando só os norte-americanos o mencionam.

Homem e mundo estão interligados e o único meio de se compreender o sujeito é a partir de sua existência concreta, nunca desvinculada do mundo, da sociedade, da cultura, da história. $\mathrm{Na}$ medida em que a experiência vivida do estigma na depressão se dá na interseção da relação homem e mundo, a cultura dá a tonalidade desta experiência, que passa a ter cores diferentes segundo os matizes da cultura onde ela é vivida.

\section{Referências}

Barbosa, L. (1992). O jeitinho brasileiro. Rio de Janeiro: Campus.

Corrigan, P. \& Lundin, R. (2001). Don't call me nuts: coping with the stigma of mental illness. Illinois: Abana Press.

DaMatta, R. (2003). A casa e a rua: espaço, cidadania, mulher e morte no Brasil. Rio de Janeiro: Rocco.

Goffman, E. (1988). Estigma: notas sobre a manipulação da identidade deteriorada. Rio de Janeiro: Guanabara.

Good, B. (2002). Stigma in HIV/AIDS and Mental Illness (Research project). Department of Social Medicine, Harvard Medical School: Boston

Gordon, R. (2002). A Assustadora História da Medicina. São Paulo: Ediouro.

Hinshaw, S. \& Cicchetti, D. (2000). Stigma and mental disorder: Conceptions of illness, public attitudes, personal disclosure and social policy. Development and Psychopathology, 12(4), 555-598.

Kleinman, A. (1988). The illness narratives: Suffering, Healing, and the Human Condition. Basic Books.

Kleinman, A. (1995). Suffering and Its Professional Transformation. Em A. Kleinman, Writing at the margin: discourse between anthropology and medicine (pp. 95-119) Berkeley and Los Angeles: University of California Press. 
Kurihara, T. et al. (2000). Public attitudes towards the mentally ill: A cross-cultural study between Bali and Tokyo. Psychiatry and Clinical Neurosciences, 54(5), 547-552.

Link, B. \& Phelan, J. (2001). Conceptualizing stigma. Annual Review of Sociology, 27(1), 363385.

Moreira, V. (1998). Una comprensión de la psicopatología desde la fenomenología de Merleau-Ponty. Revista Chilena de Psicología, 19(1), 106-112.

Moreira, V. (1999). Modos de Constitución de la Subjetividad: Una Perspectiva Fenomenológica Transcultural. Psykhe, 8(1), 27-31.

Moreira, V. (2000). Ideologia e psicopatologia: Uma discussão fenomenológica transcultural. Revista Latinoamericana de Psicopatologia Fundamental, 3(4), 80-91.

Moreira, V. (2001). Psicopatologia, fenomenologia e cultura: a contribuição de Arthur Tatossian. Revista Latinoamericana de Psicopatologia Fundamental, 4(3), 127-130.

Moreira, V. (2004). O método fenomenológico de Merleau-Ponty como ferramenta crítica na pesquisa em psicopatologia. Psicologia: Reflexão e Crítica, 17(3), 447- 456.

Moreira, V. (2006). Estigma: minha doença é invisivel. Trabalho apresentado no II Congresso Internacional de Psicopatologia Fundamental e VIII Congresso Brasileiro de Psicopatologia Fundamental. Belém, Pará.
Moreira, V. (2007). Critical phenomenology of depression in Brazil, Chile and the United States. Journal of Latin-American Fundamental Psychopathology online, 7(2), 193-218.

Moreira, V. \& Callou, V. (2006). Fenomenologia da solidão na depressão. Mental (Barbacena), 4(7), 67-83.

Moreira, V. \& Guedes, D. (2007). Largada pelo Marido! O estigma vivido por mulheres em Tianguá-CE. Psicologia em Estudo, 12(1), 71-79.

Moreira, V. \& Sloan, T. (2002). Personalidade, Ideologia e Psicopatologia Crítica. São Paulo: Escuta.

Patel, V. \& Kleinman, A. (2003). Poverty and common mental disorders in developing countries. Bulletin of the World Health Organization, 81(8), 609-615.

Scliar, M. (2003). Saturno dos Trópicos: a melancolia européia chega ao Brasil. São Paulo: Companhia das Letras.

Sennett, R. (2006). A Cultura do Novo Capitalismo. Rio de Janeiro: Record.

Tatossian, A. (2001). Sintoma e cultura. Revista Latinoamericana de Psicopatologia Fundamental, 4(3), 131-149.

Recebido em abril de 2008 Reformulado em agosto de 2008 Aprovado em setembro de 2008

Sobre as autoras:

Virginia Moreira é psicoterapeuta e supervisora clínica no enfoque humanista-fenomenológico, doutora em Psicologia Clínica pela Pontifícia Universidade Católica de São Paulo (PUC-SP), pós-doutora em Antropologia Médica pela Harvard Medical School. Professora titular do Programa de Mestrado em Psicologia da Universidade de Fortaleza - UNIFOR, onde é co-coordenadora do APHETO - Laboratório de Psicopatologia e Psicoterapia Humanista Fenomenológica Crítica. Pesquisadora da Associação Universitária de Pesquisadores em Psicopatologia Fundamental.

Thabata Castelo Branco Telles é graduanda em Psicologia na Universidade de Fortaleza (UNIFOR), bolsista de Iniciação Científica PIBIC/CNPq. Foi assistente voluntária de pesquisa no APHETO Laboratório de Psicopatologia e Psicoterapia Humanista Fenomenológica Crítica de 2006 a 2008. 
